\title{
IMPLEMENTATION OF BLENDED LEARNING THROUGH SMARTPHONE- BASED APPLICATIONS IN DISASTER IN NURSING COURSES
}

\section{ABSTRACT}

\author{
Yosi Oktarina ${ }^{1 *}$, Nurhusna ${ }^{2}$, M. A. Ade Saputra ${ }^{3}$ \\ 1,2,3 Jambi University \\ Email* : oktarinayosi@unja.ac.id
}

Introduction: Along with the development of technology, especially in the education world, blended learning method is one method that can be used by utilizing technology in the learning process. Blended learning methods with smartphone-based applications make it easy for students to access learning material and discuss directly, both with lecturers and classmates without having to face to face directly. The purpose of this study was to develop smartphone-based disaster in nursing learning applicationsand to determine the feasibility of disaster in nursing applications according to material experts, media experts, and student responses. Methods: This research design was research and development ( $R$ \& D) designby adapting the development of ADDIE (analysis, design, development, implementation, and evaluation) models.Application validation was carried out on one material expert, one media expert, and ten students of the Nursing Study Program. The technique sampling used purposive sampling. Results: The results showed that based on the material experts, the application got score 92,5\% (very feasible). Based on the assessment of media experts this application got score $93,75 \%$ (very feasible). Meanwhile, according to student's response this application got score $>75 \%$ (very feasible). Conclussions: This application should be used in blended learning especially in disaster nursing course. Thus, the nursing student learning motivation and achievment can increase.

Keywords: Application, Blended Learning, Smartphone

\section{INTRODUCTION}

Today's technological development is very rapid. With the ease of accessing these technologies, then the learning process in the world of education cannot be separated from technological progress where technologybased learning is expected to increase student motivation and learning achievement(Yaumi, 2018).

In the education world, learning methods are one of the important factors in determining student achievement.Li (2014) revealed that conventional learning and oneway learning will create saturation and hinder the development of student creativity.The results of Mulyati \& Sofia's study (2016) revealed that there was a relationship between motivation and students' level of saturation. This shows that students who have low motivation are very vulnerable to experiencing boredom in following the learning process.
The learning methods that usually used in lecture is conventional learning methods. In this learning methods, the lecturer is the center of study. They just receieve the information about the material from the lecturer. So that, it can make the students feeling bored about the study (Nursa'adah, 2014).

One of the learning methods that utilizes technological progress is blended learning.Blended learning is a mixture of learning patterns between classroom learning and online learning (Rusman, 2011). With the use of blended learning methods, the learning process can take place not only solely in the classroom.However, the learning process can take place anywhere and anytime. The results of Huda, et al's research (2018) revealed thatthere is an increase in students' understanding, ability, and creativity in program design using the blended learning method.Lam (2015) states that the use of 
blended learning methods appropriately can improve the effectiveness of teaching and learning activities.

One form of technological progress that can be utilized in blended learning methods is smartphones. Where an application related to learning is built based on a smartphone. This will certainly make it easier for students to learn not only by presenting material in the classroom.But the material can be accessed anywhere and anytime via the smartphone unlike the textbook. In addition, the existence of learning applications in smartphones is expected to increase student interest and motivation to learn. The results of the research by Nugroho \& Purbandari (2016) show that blended learning applications can be run on smartphones and make it easier for users to learn through their respective smartphones.In addition, the existence of this application facilitates the delivery of material and the implementation of examinations. The purpose of this study were to develop the learning media based on application on smartphone, to find out the feasible of the application based on expert material and media expert response, and to find out the student's response to the application.

users to learn through their respective smartphones.In addition, the existence of this application facilitates the delivery of material and the implementation of examinations. The purpose of this study were to develop the learning media based on application on smartphone, to find out the feasible of the application based on expert material and media expert response, and to find out the student's response to the application.

Although a multiple studies have shown the using of DBB as a positive and effective for enhance health outcomes, but in the patients comfort and nurse's perception context there is a paucity of literature and evidence. Therefore, it is relevant to conduct this study. This research aimed to determine the effect of disposable bed bathing method on Nurse satisfaction and the comfort of stroke patients at public hospital in Makassar.

\section{METHODS}

The design of this research was using the ADDIE (analysis, design, developement, implementation, and evaluation) development model. Altough, the research only done until the implementation step. This research was conducted in one of the Nursing Study Programs in Jambi. The sample in this study consisted of one material expert and one media expert who taught disaster in nursing courses. The sample also consisted of ten Nursing Study Program students. The technique sampling of this study was purposive sampling.The instrument used in this study is a questionnaire that was adopted from Yuntoto (2015). The Likert Scale was used in the research with the range of score 1 until 4 . The questionnaire is about material validation addressed to material experts,media validation is addressed to media experts, and student responses to the application. In this study the data were analyzed using percentage techniques that the score $76-100 \%$ was very feasible, $50 \%-75 \%$ was feasible, $26 \%-50 \%$ was enough feasible, and $<26 \%$ is not feasible. (Arikunto in Oktiana, 2012). This study has been approved by Ethics Review Boards (ERB) Committee In Medical and Health Science Faculty with the approval number 845/UN21.6/LT/2018 on August 2018.

\section{RESULT}

\section{Analysis Step}

First, the researchers investigated the needed and characteristics of students. Almost the learning methods in this course was lecture. Thus, it caused the burned with the students. When the lecturer explained about the material of study, some of students played with their smartphone. The application was made by android studio software with php programming language and mysql database and notepad + , while the hardware used includes Intel (R) core (TM) i5 CPU, 4 GB RAM, 500 GB hard 
disk. The analysis of competence and learning outcome in this application was adopted from curriculum of association of institution indonesia nursing education.

Table 1. Results of Assessment of Material Experts

\begin{tabular}{|c|c|c|}
\hline NO & STATEMENTS & Value \\
\hline 1 & The interface display is quite interesting & 4 \\
\hline 2 & An interesting media learning android application to use & 4 \\
\hline 3 & This application meets quality as a learning medium & 4 \\
\hline 4 & It can clarify the delivery of material & 4 \\
\hline 5 & It can equalize student perceptions & 4 \\
\hline 6 & It can attract student attention & 4 \\
\hline 7 & This application meets the target as a learning medium & 4 \\
\hline 8 & This application can be clearly understood by students & 4 \\
\hline 9 & This application can attract students' attention & 4 \\
\hline 10 & This application can increase student motivation & 4 \\
\hline 11 & Interesting material & 3 \\
\hline 12 & The submission of material is appropriate & 3 \\
\hline 13 & The suitability of the material is appropriate & 4 \\
\hline 14 & The material presented is clear & 3 \\
\hline 15 & The material presented is complete & 3 \\
\hline 16 & Suitability of evaluation with material and learning objectives & 4 \\
\hline 17 & Evaluationwith material and learning objectives is appropriate & 4 \\
\hline 18 & The truth of the concept of the questions & 4 \\
\hline 19 & Questionslevel of difficulty & 3 \\
\hline 20 & Variation of questions & 3 \\
\hline \multicolumn{2}{|r|}{ Total Value } & 74 \\
\hline \multicolumn{2}{|r|}{ Average Value } & 3,7 \\
\hline \multicolumn{2}{|r|}{ Percentage } & 92,5 \\
\hline
\end{tabular}

\section{The Design Step}

In the design phase, the storyboard was made, it was about the description of application. The function of storyboard was to plan the interface of the application. Beside of the making of storyboad, the selection of the material was conducted in this stage. The materials were about the mitigation and preparedness, the emergency response and the rehabilitation and reconstruction. They were selected because it is core material from disaster in nursing. The last, the 
Table 2. Results of Media Expert Assessment

\begin{tabular}{|c|c|c|}
\hline NO & STATEMENTS & Value \\
\hline 1 & Android applications can be used to deliver the message of learning material & 4 \\
\hline 2 & Learning media applications can overcome the limitations of space and time & 4 \\
\hline 3 & Android applications can be used as learning media & 4 \\
\hline 4 & The material presented is appropriate & 3 \\
\hline 5 & The appearance of the material delivered is good & 3 \\
\hline 6 & $\begin{array}{l}\text { Android applications can be used as a means of interacting between lecturers and } \\
\text { students }\end{array}$ & 3 \\
\hline 7 & The Android media application can be used easily & 4 \\
\hline 8 & Display interface is quite interesting & 3 \\
\hline 9 & An interesting media learning android application to use & 4 \\
\hline 10 & This application meets quality as a learning medium & 3 \\
\hline 11 & It can clarify the delivery of material & 4 \\
\hline 12 & It can equalize student perceptions & 4 \\
\hline 13 & It can attract student attention & 4 \\
\hline 14 & This application can be clearly understood by students & 4 \\
\hline 15 & Submission of competencies is good & 4 \\
\hline 16 & Management of material delivery is clear enough & 3 \\
\hline 17 & The questions shown are good & 4 \\
\hline 18 & Navigation buttons and menus are easy to reach & 4 \\
\hline 19 & The features in the application are running well & 3 \\
\hline 20 & The application function is in accordance with the learning function & 4 \\
\hline 21 & This application is easy to install & 4 \\
\hline 22 & You can run this application easily & 4 \\
\hline 23 & The application has worked according to its function as a learning medium & 4 \\
\hline 24 & This application can support students in learning & 4 \\
\hline 25 & This application is safe to use & 4 \\
\hline 26 & Functions and uses are in accordance with computer-based learning media & 4 \\
\hline 27 & You can learn how to use this media easily & 4 \\
\hline \multirow[t]{4}{*}{28} & You can easily remember how to use this media & 4 \\
\hline & Total value & 105 \\
\hline & Average value & 3,75 \\
\hline & Percentage & 93,75 \\
\hline
\end{tabular}

researchers prepared the questions and answers for quiz in the application. It was made from the the material that consists of made from the the material that consists of mitigation and preparedness, emergency response, and the rehabilitation and reconstruction. mitigation and preparedness, emergency response, and the rehabilitation and reconstruction.

\section{The Development Step}

This application has six main menus, named home, competency, material, quiz 
Implementation of Blended Learning Through.... (Yosi Oktarina et.al)

about us, and exit. To get into to the application, the students must sign up with the email address, student number,

name, faculty, study program, and password. When it succeeded, the student can $\log$ in.

Table 2. Results of Media Expert Assessment

\begin{tabular}{|c|c|c|}
\hline NO & STATEMENTS & Value \\
\hline 1 & Android applications can be used to deliver the message of learning material & 4 \\
\hline 2 & Learning media applications can overcome the limitations of space and time & 4 \\
\hline 3 & Android applications can be used as learning media & 4 \\
\hline 4 & The material presented is appropriate & 3 \\
\hline 5 & The appearance of the material delivered is good & 3 \\
\hline 6 & Android applications can be used as a means of interacting between lecturers and students & 3 \\
\hline 7 & The Android media application can be used easily & 4 \\
\hline 8 & Display interface is quite interesting & 3 \\
\hline 9 & An interesting media learning android application to use & 4 \\
\hline 10 & This application meets quality as a learning medium & 3 \\
\hline 11 & It can clarify the delivery of material & 4 \\
\hline 12 & It can equalize student perceptions & 4 \\
\hline 13 & It can attract student attention & 4 \\
\hline 14 & This application can be clearly understood by students & 4 \\
\hline 15 & Submission of competencies is good & 4 \\
\hline 16 & Management of material delivery is clear enough & 3 \\
\hline 17 & The questions shown are good & 4 \\
\hline 18 & Navigation buttons and menus are easy to reach & 4 \\
\hline 19 & The features in the application are running well & 3 \\
\hline 20 & The application function is in accordance with the learning function & 4 \\
\hline 21 & This application is easy to install & 4 \\
\hline 22 & You can run this application easily & 4 \\
\hline 23 & The application has worked according to its function as a learning medium & 4 \\
\hline 24 & This application can support students in learning & 4 \\
\hline 25 & This application is safe to use & 4 \\
\hline 26 & Functions and uses are in accordance with computer-based learning media & 4 \\
\hline 27 & You can learn how to use this media easily & 4 \\
\hline 28 & You can easily remember how to use this media & 4 \\
\hline & Total value & 105 \\
\hline & Average value & 3,75 \\
\hline & Percentage & 93,75 \\
\hline
\end{tabular}


Table 3. The comment and Suggestion From Material Expert and Media Expert

\begin{tabular}{ll}
\hline \multicolumn{1}{c}{ Reviewer } & \multicolumn{1}{c}{ Comment and Suggestion } \\
\hline Material expert and Media expert & The referrences of the material must be added \\
& The material should be completed \\
& The quiz must be updated and added \\
& The main display should be made more \\
& dynamic \\
& The description of wrong answer should be \\
displayed
\end{tabular}

Table 4. Results of Student Assessment Responses

\begin{tabular}{clcc}
\hline NO & \multicolumn{1}{c}{ STATEMENTS } & Amount & \% \\
\hline $\mathbf{1}$ & $\begin{array}{l}\text { Android applicationcan be used to convey messages of learning } \\
\text { material }\end{array}$ & 35 & 88 \\
\hline $\mathbf{2}$ & $\begin{array}{l}\text { Learning media applicationcan overcome the limitations of space } \\
\text { and time }\end{array}$ & 35 & 88 \\
\hline $\mathbf{3}$ & Android applicationcan be used as learning media & 38 & 95 \\
\hline $\mathbf{4}$ & The material presented is appropriate & 31 & 78 \\
\hline $\mathbf{5}$ & The appearance of the material delivered is good & 31 & 78 \\
\hline $\mathbf{6}$ & $\begin{array}{l}\text { Android applications can be used as a means of interacting between } \\
\text { lecturers and students }\end{array}$ & 36 & 90 \\
\hline $\mathbf{7}$ & The Android media application can be used easily & 36 & 90 \\
\hline $\mathbf{8}$ & Display interface is quite interesting & 33 & 83 \\
\hline $\mathbf{9}$ & Interesting media learning android application to use & 35 & 88 \\
\hline $\mathbf{1 0}$ & This application meets quality as a learning medium & 34 & 85 \\
\hline $\mathbf{1 1}$ & This application can shorten learning time & 35 & 88 \\
\hline $\mathbf{1 2}$ & This application can increase the role of students & 35 & 88 \\
\hline $\mathbf{1 3}$ & Navigation buttons and menus are easy to reach & 36 & 90 \\
\hline $\mathbf{1 4}$ & The features in the application are running well & 37 & 93 \\
\hline $\mathbf{1 5}$ & The application function is in accordance with the learning function & 34 & 85 \\
\hline $\mathbf{1 6}$ & This application is easy to install & 37 & 93 \\
\hline $\mathbf{1 7}$ & You can run this application easily & 37 & 93 \\
\hline $\mathbf{1 8}$ & $\begin{array}{l}\text { The application has worked according to its function as a learning } \\
\text { medium }\end{array}$ & 36 & 90 \\
\hline $\mathbf{1 9}$ & Submission of material is right & 33 & 83 \\
\hline & & & \\
\hline & & 36 & \\
\hline
\end{tabular}


Table 5. The comment and Suggestion From The Students

\begin{tabular}{ll} 
Reviewer & Comment and Suggest \\
\hline Students & The aplication is good enough,but the pictures \\
should be added in this application. So, it can be \\
more interesting. \\
The application should be used in all operating \\
system of smartphone \\
The chat feature shold be added in this \\
application. Hence, the students can make \\
consultation with the lecturer
\end{tabular}

by entering the email and password that had been registered.

\section{Main Menu / Home Display}

To be able to enter the main menu, students must press the login button. This main menu contains 6 menu choices, namely Home, Competence, Material, Quiz, About Us, and Exit

\section{Competency Menu Display}

On the competency screen display, this application makes learning achievements in the Disaster in Nursing course where there are five learning outcomes in this course. The learning outcome was adopted from the curriculum of Assosiation of Indonesian Instituion Nursing Education.

\section{Material Menu Display}

The application contains three materials that consists of mitigation and preparedness, emergency response, and rehabilitation and reconstruction. The students can study and read about it from this menu by using their smartphone.

\section{Quiz Menu Display}

Thequiz menu in this application contains fifteen questions. The quiz was made from the material. The quiz also comes with a time that shows the length of time the questions were worked on. At the end of the quiz work, the correct number of answers that have been done will appeared. So that, the students will know about their answer. The quiz also can be updated by the admin.

\section{About Menu Display}

This menu contains the names of researchers and their institutions.

\section{Exit Menu}

When the students tap this menu, the students can exit from this application.

\section{The Implementation Step}

Validation test results by material experts can be seen in the table 1. Based on Table 1, an overall assessment by material experts was obtained with a total value of 74 in 20 statement items with an average value of 3.7. Based on the the percentage, this application get an assessment of $92.5 \%$ which belongs to the very feasible category.

Validation test results by media experts can be seen in the table 2. Based on table 2 it was obtained an assessment by media experts with a total value of 105 against 28 statement items. While the average value obtained in this application is 3.75. Based on the assessment of the percentage of this application received an assessment of $93.75 \%$ which is included in the category of very feasible.

The comment and suggestion from the material expert and media expert can be seen in table 3.

Validation test results by students can be seen in the table 4. Based on the table 4, it can be seen that all statements get a positive response 
very feasible because each statement gets a percentage above $75 \%$.

The comment and suggestion from the students can be seen in table 5 .

\section{DISCUSSION}

This application was created with the aim to implement a blended learning system. Where the learning combines the conventional learning systems with e-learning whereas it produced the product. The product is a learning media in the form of smartphonebased applications with the Android operating system. Given that in this technological era, the smartphone usage cannot be released in daily usage.

This disaster in nursing learning application contains several menus such as competence, material, quizzes, and about applications. The competency menu is about student learning outcomes. The material contains about mitigation and preparedness, emergency response, and rehabilitation and reconstruction. While the quiz menu contains exercises that can be done by students. About menu contains the name and institution of the researcher.

Based on assessments made by material experts, experts, media, and student responses regarding the application, it can be concluded that this application is very feasible to be used as a learning medium in a blended learning system.According to Habitzel, Mark, Stehno\&Prock (2006) effective learning can be realized through smartphone-based learning applications or commonly referred to as mobile learning.The assessment results from material experts received a score of $92.5 \%$. The assessment results from media experts are 93.75\%.While based on responses from students, each statement item gets an assessment above $76 \%$. Another research was conducted by Klimova (2017), the finding indicated that the use of mobile phones/smartphones and their apps contributed to possitive effects on learning and increased the motivation to study.
The advantages of this application is the use of this application is quite easy and can be used anywhere. Smartphone-based applications or mobile learning can facilitate the needs of students in learning material at any time without any time and place restrictions (Rahmelina, 2017). The presence of smartphone-based applications make chances to study about the material whenever and wherever (Wirawan, 2011). The research that conducted by Anshari (2017) found that the students used their smartphones to access the teaching materials and supporting information. Besides, they used smartphones because of the conveinence, portability, multitasksm and enviromentally friendly. In this research, the application does not only contain material but also contains quizzes about disaster in nursing material that is completed with work time. After the problem is done, the number of student scores will appear based on the correct answer. The questions on the quiz can be updated regularly. Meanwhile, the lack of this application is that this application can only be used if connected to the internet. It can only be used on smartphones with an Android system. Besides Anshari (2017) explained that the challenges of the using of smartphone are the distraction and the decrease quality of face to face.

Limitations in this study are that the material available in this application is limited to only covering. In addition, the application testing is only carried out on one lecturer as a media expert, one lecturer as a material expert and ten students.

\section{CONCLUSIONS}

The conclusion in this study is that based on the results of the assessment of material experts and media experts this application is feasible for used. This application also gets positive responses from students. As for suggestions for the development of this application so that the material in this application can be equipped with learning and animation videos so students will be more interested in using this 
application. In addition, it is expected that this application can be applied to all smartphones, not limited to smartphones with android operating systems. In spite of, This application should be used in blended learning especially in disaster nursing course. Thus, the nursing student learning motivation and achievment can increase.

\section{REFERENCES}

Anshari, Muhammad \& Almunawar, Mohammad Nabil \& Shahrill, Masitah \& Wicaksono, Danang \& Huda, Miftachul. (2017). Smartphones usage in the classrooms: Learning aid or interference? Education and Information Technologies. 22. 10.1007/s10639-017-9572-7.

Habitzel, K., Mark, T.D, Stehno, B., \& Prock, S. 2006. Microlearning; Emerging concepts, practices and technologies after e-learning. Proceeding of Micro learning 2005 Learning \& Working in New Media, In conference Series: Innsbruck University press: Retreived on 22 September 2018 From http:// www.microlearning. org/micropapers/ microlearning 2005- proceedings digit aversion. Pdf.

Huda, C., Hudha, M.N., Ain, N., Nandiyanto, A.B.D., Abdullah, A.G., Widiaty, I. 2018. The Implementation of Blended Learning Using Android-Based Tutorial Video in Computer Programming Course II. IOP Conf. Ser. Mater. Sci. Eng. 288, 012163. https://doi.org/10.1088/1757$\underline{899 X / 288 / 1 / 012163}$

Klimova, Blanka. 2017. Mobile Phones and/or Smartphones and Their Apps for Teaching English as Foreign Language. Education and Information
Technologies.

$1-9$.

Doi

10.1007/s10639-017-9655-5.

Lam, J., 2015. The Student Experience of A Blended Learning Course In Hong Kong. International Journal of Technical Research and Application 20, 04-13

Li, W.Y. 2016. Transforming Conventional Teaching Classrom to LearnerCentered Teaching Classroom Using Multimedia-Mediated Learning Module. International Journal of Information and Educational Technology 6, 2

Mulyati, L., Sofia, N.2016. Motivation, The Role of Tutor, and Saturation of Studetnts with The Implementation of Competency-Based Curriculum in Kuningan Health College. Journal of Injec 1, 1-6.

Nugroho, R.S., Purbandari, N., 2016. Implementation of Smartphone-Based Blended Learning Multimedia for Enrichment of Learning in XYZ Schools.Journal of Science and Technology3, 37-48

Nursaadah. 2014. The Effect of Learning Method and Student's Attitude on Natural Science Course To Learning Outcomes. Journal Formative4(2) : 112-123

Rahmelina. 2017. Design of Android Based Mobile Learning in The Course of Operating Systems at STMIK Indonesia. Jurnal Informatika 11(2).

Rusman. 2011.Learning Models:Improving Teacher's Profesionalism. Jakarta : PT Raja Grafindo Persada

Wirawan, W.P. 2011. The Developement of The Ability of Web Based E-Learning into M-Learning. Journal of Informatica People 2 (4).

Yaumi. 2018. Media dan Teknologi Pembelajaran. Jakarta : Prenada Media

Grou. 